\title{
Variable Ratio Hydrostatic Transmission Simulator for Optimal Wind Power Drivetrains
}

\author{
Jose M. Garcia-Bravo, ${ }^{1}$ Ivo N. Ayala-Garcia, ${ }^{2}$ and Juan L. Cepeda-Aguilar ${ }^{3}$ \\ ${ }^{1}$ Purdue University, West Lafayette, IN, USA \\ ${ }^{2}$ Universidad Tecnológica de Querétaro, Santiago de Querétaro, QRO, Mexico \\ ${ }^{3}$ Universidad de los Andes, Bogotá, Colombia
}

Correspondence should be addressed to Jose M. Garcia-Bravo; jmgarcia@purdue.edu

Received 20 May 2017; Accepted 20 July 2017; Published 28 August 2017

Academic Editor: Lei Chen

Copyright (C) 2017 Jose M. Garcia-Bravo et al. This is an open access article distributed under the Creative Commons Attribution License, which permits unrestricted use, distribution, and reproduction in any medium, provided the original work is properly cited.

\begin{abstract}
This work presents a hydromechanical transmission coupled to an electric AC motor and DC generator to simulate a wind power turbine drive train. The goal of this project was to demonstrate and simulate the ability of a hydrostatic variable ratio system to produce constant electric power at varying wind speeds. The experimental results show that the system can maintain a constant voltage when a $40 \%$ variation in input speed is produced. An accompanying computer simulation of the system was built and experimentally validated showing a discrete error no larger than $12 \%$. Both the simulation and the experimental results show that the electrical power output can be regulated further if an energy storage device is used to absorb voltage spikes produced by abrupt changes in wind speed or wind direction.
\end{abstract}

\section{Introduction}

Wind power generators are a technology that contributes to sustainable energy and low impact to the environment. However, some of the challenges that the current wind power industry face are high installation and maintenance costs and reliability issues [1-4]. To be able to reduce the cost of wind power energy in general, the wind power industry must invest resources in developing wind power technologies that decrease the total cost of the produced energy. This can be done if wind power turbines operate efficiently at broader wind speed ranges, while maintaining optimum electrical generator shaft speeds, so they can generate more electric power regardless of the wind speed. There is a great impact on the turbine reliability when major components of the wind power turbine like the gearbox or the generator fail because this creates an extended mean time to repair (MTTR) [4-6]. Therefore, reducing failure and maintenance of these major components reduces the cost of operation of the wind power turbine, which in turn reduces the cost of energy itself.

The power coefficient $C_{p}$ in (1) is a parameter used for measuring the efficiency of the wind energy captured by the turbine; this coefficient represents the ratio of the mechanical power output of the turbine to the power input from the wind.

$$
C_{p}=\frac{\eta_{d}}{\eta_{m} \eta_{g}} .
$$

$\eta_{d}$ is the aerodynamic efficiency of the turbine and $\eta_{m}$ and $\eta_{g}$ are the electric generator efficiency and the gearbox efficiency, respectively [7]. The maximum theoretical achievable $C_{p}$ is $59 \%$; this condition, which is derived from fluid mechanics principles is known as the Betz limit [7]. The direct consequence of this limit is that no more than $59 \%$ of the available power in the wind can be captured.

The tip speed ratio $\lambda$ (see (2)) is parameter used to define the ratio between the tangential velocity of the blade and the wind speed. The family of plots shown in Figure 1 illustrates the effect of the tip speed ratio on the power coefficient $C_{p}$ for various pitch angles of the same blade.

$$
\lambda=\operatorname{TSR}=\frac{\omega R}{V}=\frac{2 \pi R N}{V},
$$

where $\omega$ is the rotational speed of the blades, $R$ is the radius of the wind turbine, and $V$ is the wind speed. As 


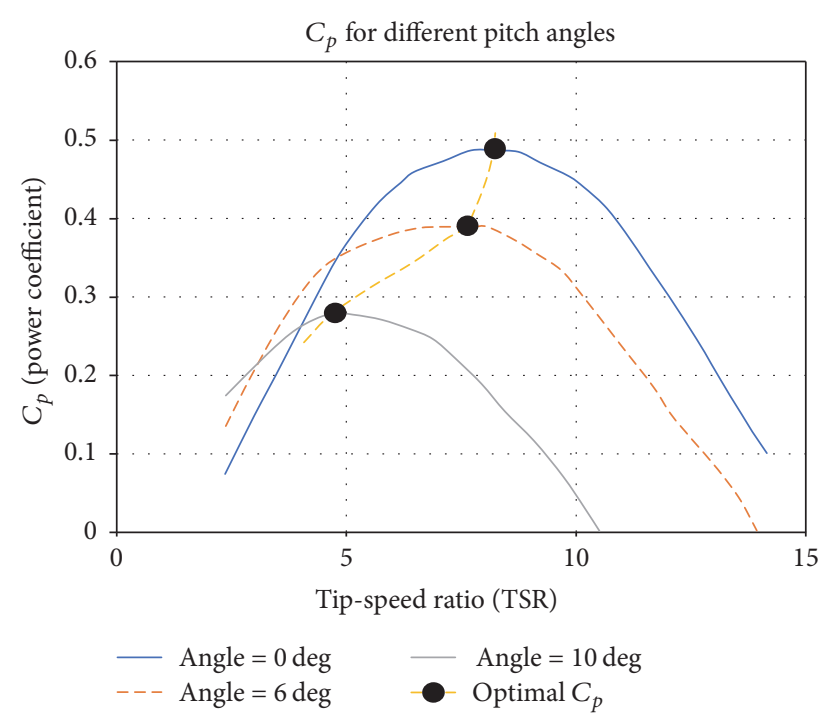

FIgURE 1: Power coefficient versus tip speed ratio [8].

the wind speed varies, the pitch angle of the blade needs to be adjusted to operate at the optimal $C_{p}$. Inevitably, when the wind speed varies, the shaft speed of the generator also changes because the rotor's shaft is directly (direct drive) or indirectly (gearbox) coupled to the generator's shaft. That means that the electric generator will produce electric power at variable frequencies that need to be conditioned using power electronics to match the constant frequency standard of the electric grid. The challenge of using this approach is the increased complexity, cost, weight, and size of the wind turbine components and it reduces its efficiency and reliability. Additionally, most common current electric generators operate more efficiently at their constant rated shaft speed, which is normally a single value between 1800 and 2200 RPM. This is particularly true, for field induced generators, but it also affects permanent magnet motors because the amount of power produced is proportional to the input shaft speed.

Various studies [9-15] have proposed the use of hydrodynamic, hydrostatic, or mechanical continuously variable transmissions (CVT) instead of using fixed or variable speed gearboxes; the objectives of incorporating a CVT to replace the gearbox are to improve the overall reliability of the wind turbine, reduce the weight of the nacelle components, reduce down-time, and significantly reduce the cost of installation and operation. The use of power electronics systems used to convert the electric output of the generator with the grid is known [11] to reduce the captured wind power in the $93-94 \%$ range for wind speeds between 6 and $11 \mathrm{~m} / \mathrm{s}$.

When replacing the fixed ratio mechanical gearbox or the power electronics systems in a wind power drive train with a CVT, the overall efficiency of the turbine will be increased because the generator's shaft will turn at its optimal speed while maintaining an ideal tip speed ratio $\lambda$ to achieve a maximum power coefficient $C_{p}$ [7]. While the hydraulic hydrostatic transmission will introduce a power loss due to its overall efficiency of approximately $86-93 \%$, the cost, reliability, and maintenance benefits of implementing this solution would offset the $\sim 1-12 \%$ loss in energetic efficiency.

The hydrostatic transmission will be the focus of this project because it is a technology that has been proven to be reliable and cost effective. Additionally, hydrostatic transmissions allow novel and flexible designs where the generator is placed at the floor level for easier, less costly, and safer maintenance. A hydrostatic transmission is a variable speed rotary drive that consists of one or more positive displacement hydraulic pumps connected to one or more positive displacement hydraulic motors. The main function of the hydrostatic transmission is to convert mechanical power into hydraulic power (pressure and flow) and after transmitting it through piping or hoses convert it back into mechanical power to be used in an application. A hydrostatic transmission fitted with a fixed or a variable displacement (flow) pump and a fix or a variable displacement motor allows the output shaft to deliver a nearly constant power at varying speeds, similar to the requirement for wind power turbines.

The work by Thul et al. [9] provided theoretical evidence that these types of transmissions would dampen the large torque impulses created from wind gusts and turbulence, which translates into lower loads on the bearings of the generator, therefore increasing their life. Preliminary simulation results from Thul et al. [9] and Yang et al. [12] revealed that a wind power turbine fitted with pitch control and or a continuously variable transmission could operate at an optimal power coefficient even at speeds close to the cut in speed (minimum operating speed); this would allow capturing more energy from the wind at these lower speeds and capturing more power at the turbine's rated speed.

The main challenge for using hydrostatic transmissions in wind power generation is the lack of pumps and motors that can match the power requirements of current mid-sized $(250 \mathrm{~kW}$ to $750 \mathrm{~kW})$ and large sized wind power turbines (750 kW or more); most of the larger displacement pumps are rated for a little less than $250 \mathrm{~kW}$. Researchers investigating the use of hydrostatic transmissions for wind power use have recurred to three alternatives: (1) limiting the wind power capacity to less than $250 \mathrm{~kW}$ [9], (2) using more than one pump and more than one motor to meet the flow requirements of larger size wind turbines [11], and (3) designing hydrostatic transmissions with an experimental large displacement pump. Wind power turbines larger than $150 \mathrm{~kW}$ are typically fitted with three phase alternating current (AC) generators at $690 \mathrm{~V}$; this current is then sent to a transformer to increase the voltage several thousand volts up to 30,000 volts, making it up for transmission in high voltage lines [16].

The aim of this project was to design, build, and test a small scale experimental bench system with the flexibility to simulate various wind speed profiles. At the same time, the principal objective was to integrate control algorithms for measuring and demonstrating a variable ratio hydrostatic transmission.

The design of the simulator encompasses two associated fields: hydraulics and electrical systems. The first system is involved in the transmission of the mechanical energy from the wind turbine into the electrical generator by using a hydrostatic transmission. The second system, is in charge of 


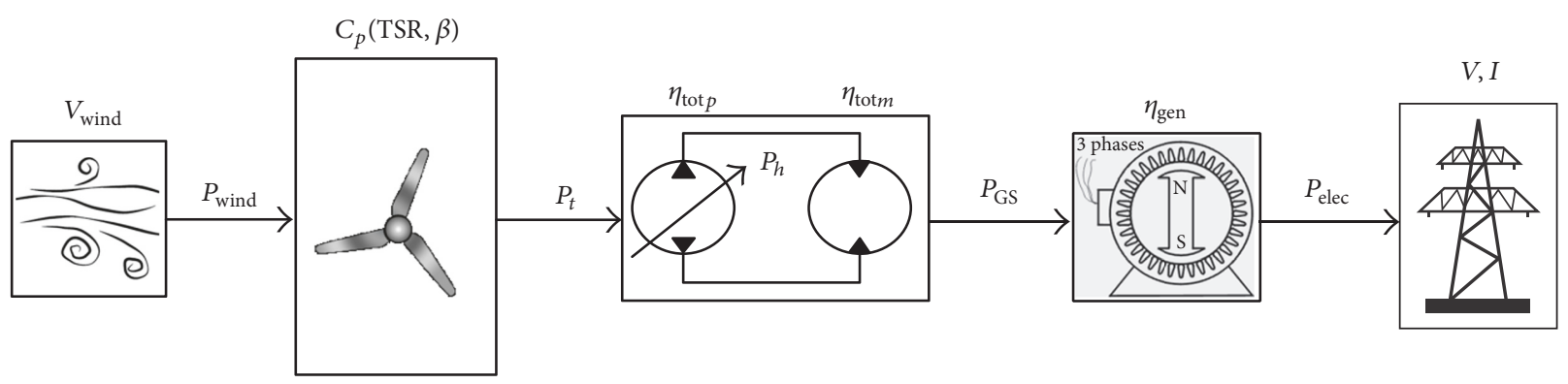

FIGURE 2: Power flow through the system.

controlling the different gear ratio of the system to maintain a constant voltage output and also adjusting the simulated wind speed.

\section{Theoretical Approach}

This study section focuses on the flow of power through the system, as it is depicted in Figure 2. The magnitude of the power available in the wind $P_{\text {wind }}$ is quantified using the expression in

$$
P_{\text {wind }}=\frac{1}{2} \rho A V^{3}
$$

where $\rho$ is the density of the air at the altitude at the wind turbine is location, $A$ is the transversal area that is being passed by the wind, in this case the area swept by the blades while it is spinning, and $V$ is the velocity of the wind.

The power that the turbine extracts from the wind $\left(P_{t}\right)$, as it was mentioned in the background section, is calculated using the power coefficient using (3):

$$
P_{t}=C_{p}(\mathrm{TSR}, \beta) P_{\text {wind }}=\frac{1}{2} C_{p} \rho A V^{3} .
$$

The power extracted by the turbine is equal to the power on the shaft, if the rotor is assumed to be rigid (no torsion).

$$
P_{t}=\omega_{\mathrm{tS}} T_{\text {aero }}
$$

Then, the mechanical power from the rigid shaft is converted into hydraulic power by a hydrostatic pump.

$$
P_{h}=\eta_{p_{\text {tot }}} P_{t} .
$$

And the hydraulic power is defined as

$$
P_{h}=\Delta p Q
$$

The total efficiency of the pump $\left(\eta_{p_{\text {tot }}}\right)$ is the product between the volumetric $\left(\eta_{\mathrm{vol}}\right)$ and the mechanical $\left(\eta_{\mathrm{mec}}\right)$ efficiencies of the pump. The volumetric efficiency of a hydraulic machine is defined as the ratio between the real flow produced and the theoretical flow. Meanwhile, the mechanical efficiency is equal to the ratio between the real torque and the theoretical torque required to drive the pump.
$D$ is the hydraulic machine displacement and $n$ is the shaft speed in RPM.

$$
\begin{aligned}
\eta_{\mathrm{vol}} & =\frac{Q}{D n}, \\
\eta_{\text {mec }_{p}} & =\frac{D \Delta p}{T} .
\end{aligned}
$$

Once the fluid is pressurized by the pump, it is transported by the hoses to the hydraulic motor where the power is transformed back into mechanical power and coupled to an electrical generator shaft.

$$
P_{\mathrm{GS}}=\eta_{\mathrm{tot}_{m}} P_{h}
$$

The total efficiency in the case of the hydraulic motor is similar to the pump; the total efficiency is the same product between the volumetric and mechanical efficiency. The volumetric efficiency is expressed the same way; the difference is in the mechanical efficiency; the expressions are reversed.

$$
\eta_{\mathrm{mec}_{m}}=\frac{T}{D \Delta p},
$$

where $T$ corresponds to the ideal hydraulic machine's shaft torque and $\omega$ is the rotational speed. Power on the generator shaft is expressed in the following equation.

$$
P_{\mathrm{GS}}=\omega_{\mathrm{GS}} T_{\text {elec }}
$$

Finally, the energy is transformed from mechanical power to electrical power by means of the generator using the electromagnetic theory.

$$
P_{\text {elec }}=\eta_{\text {gen }} P_{\mathrm{GS}}
$$

\section{Materials and Methods}

3.1. Wind Speed. The rotational energy generated by a wind power turbine is proportional to the kinetic energy in the wind. The simulator replaces the wind turbine by a Brook Crompton Americas, 3-phase, $60 \mathrm{~Hz}$, NEMA 56 electric motor (BF4N.33-2). The variation of the kinetic energy of the wind is simulated with the inclusion of a Teco Westhinghouse electric inverter (JNEV-101-H1). The electric inverter varies the frequency at the motor power lines from $0 \mathrm{~Hz}$ 


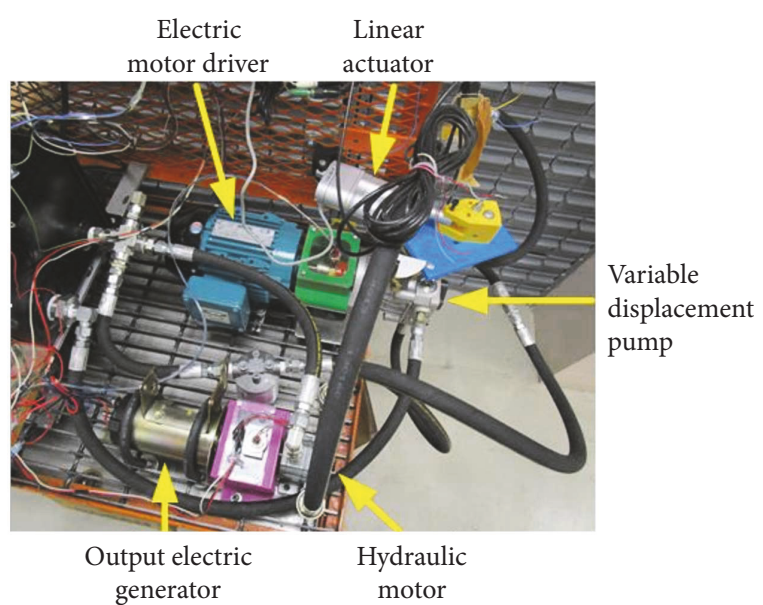

Figure 3: Test bench hardware setup.

to its nominal value of $60 \mathrm{~Hz}$, proportionally affecting the rotational shaft speed of the motor between approximately 0 to $1800 \mathrm{rpm}$. These values of the frequency are assumed to be linearly proportional to the input wind speed, where $0 \mathrm{~Hz}$ corresponded to 0 wind speed and $60 \mathrm{~Hz}$ corresponded to the maximum permissible wind speed on a small wind power turbine $(<50 \mathrm{~kW})$ of approximately $15 \mathrm{~m} / \mathrm{s}$.

3.2. Hydraulic System. The electric motor is coupled to a $10.3 \mathrm{cc} / \mathrm{rev}$ variable displacement pump (Hydro-Gear, PG1HCC-DL1X). This is the first component of a hydrostatic transmission, transducing the mechanical power from the electric motor into hydraulic power. The hydraulic power is then transmitted to a fixed displacement hydraulic gear motor (Double A Hydraulics, MFG 2), which converts the hydraulic energy back into mechanical energy. The hydraulic motor is coupled to a permanent magnet generator (GS Electric, B4CPM-102T) which converts the mechanical energy into electrical energy.

The variable displacement hydraulic pump regulates the amount of energy transferred to the hydraulic motor by adjusting the angle of the swashplate, hence adjusting the volumetric flow rate delivered by the pump. Regardless of the mechanical energy generated by the electric motor, the hydraulic power delivered to the hydraulic motor is adjusted to maintain an approximated constant power. The adjustment of the swashplate is accomplished by means of a linear actuator attached to the pump trunnion arm. The simulator regulates the angle according to the amount of the electrical energy required at the output of the DC generator. The rotation of the generator's shaft generates a current proportional to the rotational speed, which in turn is rectified into a DC signal (Figure 3 ).

3.3. Control. The wind speed is simulated by adjusting the driving frequency of the 3-phase electric motor. The frequency range can be adjusted from 0 to $60 \mathrm{~Hz}$. The actual rotation speed depends on the mechanical load applied at the rotor. The wind profile tested is described in Section 5.
The driving frequency is controlled by using the EI. The frequency can be manually adjusted using a knob or via an analog signal at a predefined input port of the EI. The convenience of using an analog signal to control the frequency relies on the ability to implement an automatic system that programmatically changes the frequency following a given pattern or data set. This feature allows the system to simulate a wind profile.

Mechanical coupling between the electric motor and the hydraulic pump is achieved by the use of a jaw type couplings. These couplings include an elastomer insert between metal hubs. The insertion of the nonmetallic elastomer creates the opportunity to place a proximity sensor (Allen-Bradley, $872 \mathrm{C}-\mathrm{D} 3 \mathrm{NN} 12-\mathrm{D} 4)$ to measure the rotational speed. A revolution of the rotor is measured by the number of teeth sensed. On a three teeth hub, a full revolution occurs when six teeth are sensed.

The rotational displacement of the rotor is transduced into hydraulic flow and pressure at the variable hydraulic pump. This variable capability is of crucial importance for the system. By adjusting the flow, the energy transduced by the electric generator can be controlled, hence maintaining a constant output voltage independent of the wind speed.

The flow rate at variable hydraulic pump is achieved by adjusting the angle of the swashplate. The swashplate is attached to a trunnion arm that can be externally manipulated to control the flow. A linear actuator is connected to the trunnion arm. The direction and rate of displacement of the actuator are performed by a power driver connected to a personal computer.

The hydraulic pump is connected to a hydraulic motor via hydraulic hoses. A flow meter and pressure sensor measure these two parameters at one of the hoses that connect the pump to the motor. Due to the nature of the system, the hydraulic flow is allowed to go in only one direction.

The hydraulic motor then transfers the energy to an electric generator. The mechanical coupling is accomplished through a jaw type coupling, where the rotational speed is measured using a hall effect sensor (Cherry, MP1005).

The permanent magnets of the electric generator create the excitation field necessary to induce current on the stationary coil. Additionally, a rectifier circuit converts the resulting AC voltage from the coil into a DC signal which is measured using the voltmeter (Tenma, 72-7735). Figure 4 shows a schematic representation of the hardware components.

3.4. Instrumentation and Control Algorithm. The instrumentation includes two hall effect sensors, a flow meter, and a pressure sensor. All these signals are sensed using a data acquisition card DAQ (NI USB-6221) connected to the personal computer. The multimeter is connected directly to the PC via its serial port.

Two output signals are controlled by the system, driving frequency at the EI, and flow rate at the hydraulic pump. The frequency is adjusted by an analog signal generated at the DAQ card, while the flow rate is controlled by adjusting the length of the linear actuator connected to the trunnion of the hydraulic pump. 


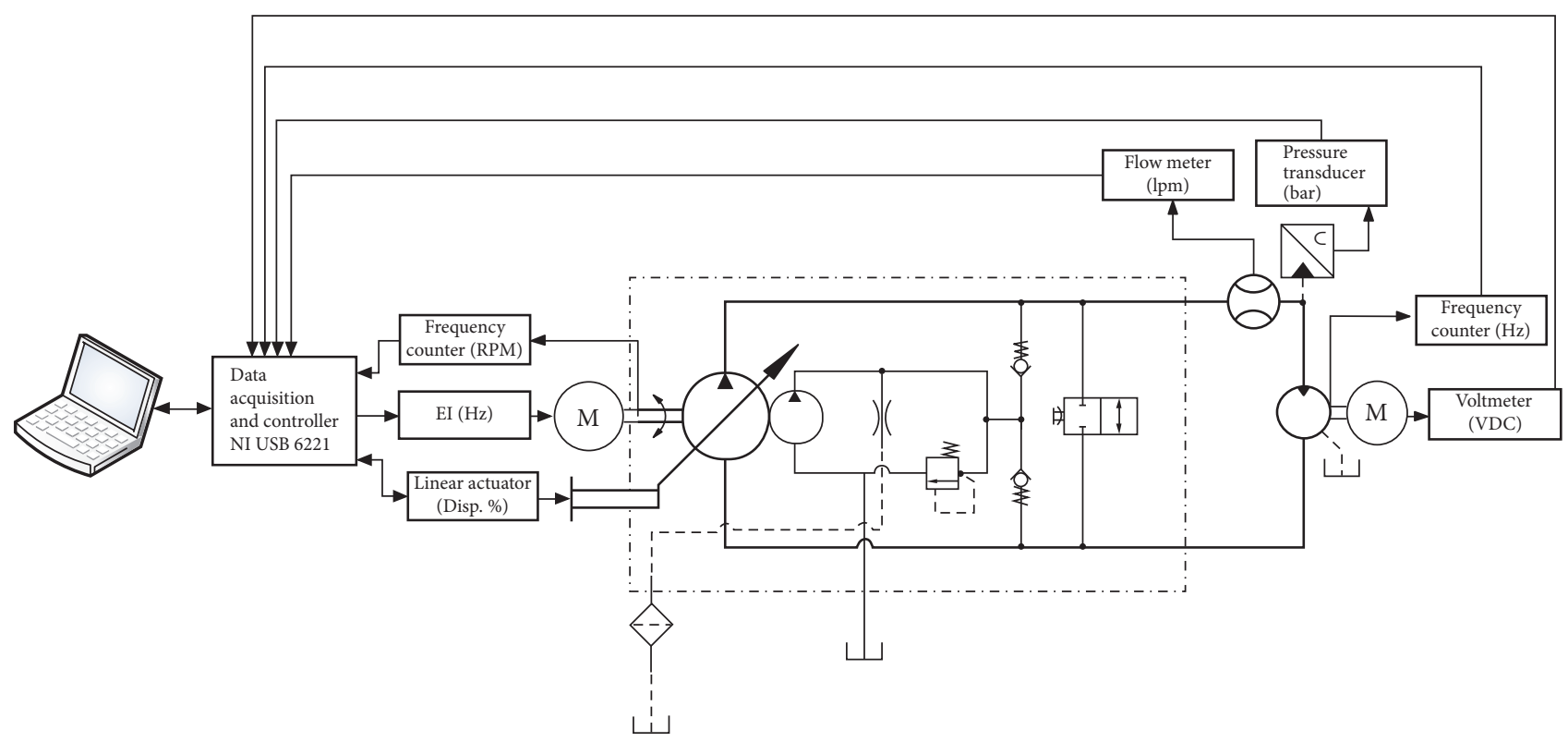

FIGURE 4: Schematic representation of test bench hardware setup.

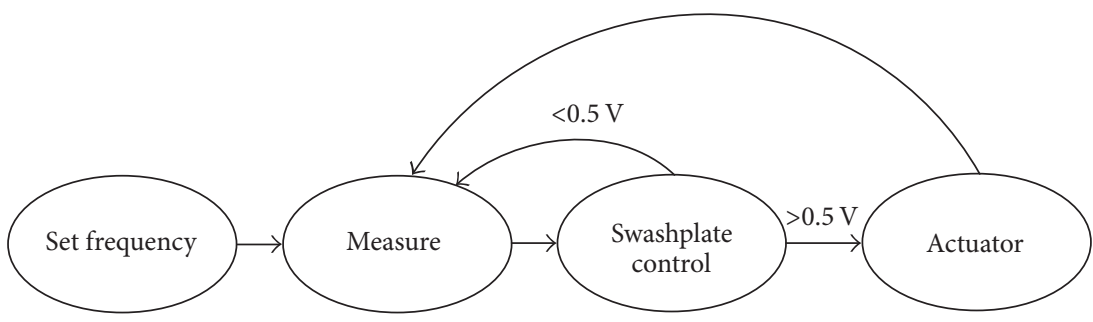

Figure 5: Control flow path.

The control algorithm follows a state machine architecture. Each state corresponds to a particular activity in the system as presented in Figure 5. The system starts by setting the desired frequency at the motor driver. This frequency corresponds to a particular simulated wind speed. Then, different variables are measured in the system: selected frequency, revolutions per minute (RPM) at the motor driver, RPM at the generator, hydraulic flow rate, pressure at outlet of the variable displacement pump, actuator position, and voltage at the electric motor.

The control of the variable displacement hydraulic pump is achieved by adjusting the swashplate using a linear actuator. A proportional control commands the adjustment of the actuator stroke length, either reducing or increasing it. The adjustment is performed until the signal error reaches $\pm 0.5 \mathrm{~V}$ from the desired output voltage at the DC generator.

\section{System Characterization}

4.1. Hardware Characterization. The system was characterized to identify its operating range: frequency and DC output voltage. In the first series of tests, the angle of the variable swashplate was kept constant, starting at $25 \%$ of its maximum flow, increasing in steps of $25 \%$, up to $100 \%$ displacement.

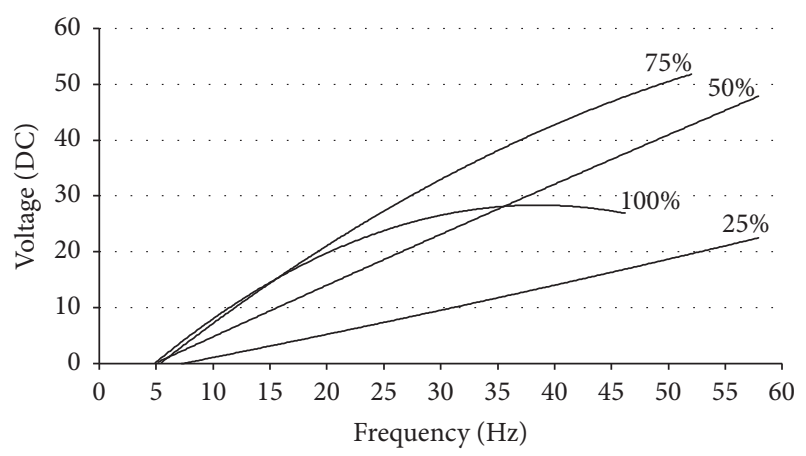

FIGURE 6: Voltage generation at different swashplate angles.

The control system was disabled and the electric load was the voltmeter. Figure 6 shows the polynomial fits of the collected voltage data; the fitted data is shown here to cleanly depict the frequency trends at various pump displacement values. It this figure, it can be seen that at $25 \%$ pump displacement the system can generate a maximum of $22 \mathrm{~V}$. The maximum output voltage increases with the swash plate angle, up to $52 \mathrm{~V}$. It is important to notice that increasing the swash plate angle does not necessarily implies reaching a higher output voltage. 


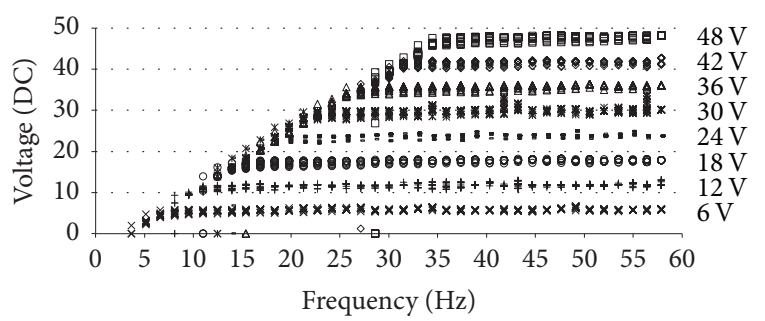

FIGURE 7: Voltage generation for different frequencies.

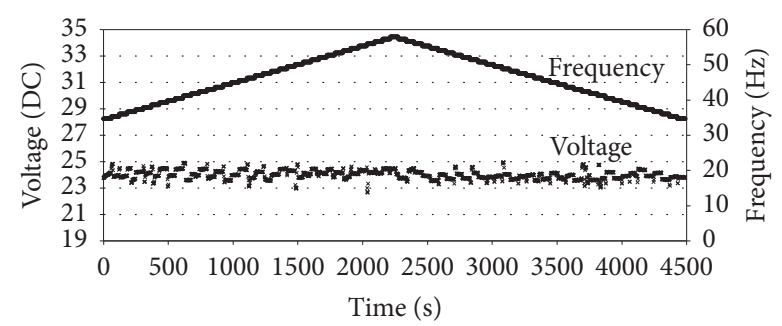

Figure 8: Voltage control for a constant ratio of frequency change.

This can be observed for the case when the angle is $100 \%$. The voltage follows a similar path as per $75 \%$; however at around $20 \mathrm{~V}$ the voltage decreases as the frequency increases. This can be explained because of the reduced capacity (displacement) of the hydraulic motor with respect to the pump. Because of its smaller size, the motor cannot admit $100 \%$ of the pump output; this creates an increase in the system pressure that in turn dampens the hydraulic pump, reducing the speed of the rotor. Hence, a hydraulic motor with a larger input capacity can produce a larger output voltage.

Due to the hardware constrains, it was decided to operate the system with a maximum output voltage of $48 \mathrm{~V}$ to avoid overheating of the input electric motor when the damping increases at the hydraulic pump. A second set of tests investigated the performance of the control at different output voltages. The frequency decreases on each case steadily by $1.5 \mathrm{~Hz}$ from $58 \mathrm{~Hz}$ down to the point where the rotor at the electric motor stops rotating due to damping. From Figure 7 it can be seen that there is a minimum voltage that any given frequency can generate, which follows the following equation.

$$
V_{\min }=1.5 F-4.5 \text {, }
$$

where $V_{\min }$ represents the minimum DC voltage and $F$ is the generator's frequency in $\mathrm{Hz}$.

To evaluate the performance of the controller, the output voltage set-point was fixed to $24 \mathrm{~V}$, while the input frequency was varied between 35 and $58 \mathrm{~Hz}$ every $60 \mathrm{~s}$, as shown in Figure 8. In all the cases the electric load at the DC generator was the voltmeter with a $10 \mathrm{M} \Omega$ input impedance.

Figures 9 and 10 present a detailed view of the test when the input frequency was increased and decreased, respectively. Right after the frequency changes, the output voltage increases its error relative to the set-point. Few seconds later, the system adjusts the flow to reduce this error to a maximum of $\pm 0.5 \mathrm{~V}$ error band.

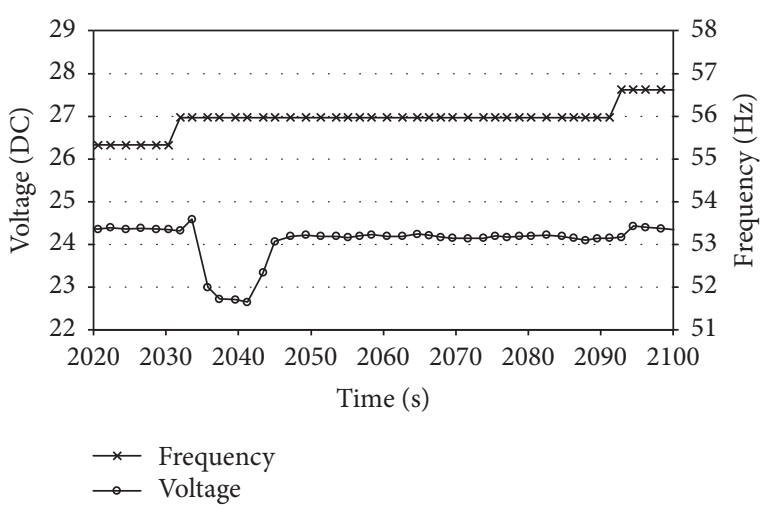

FIGURE 9: System adjustment as the frequency increases by $1.5 \mathrm{~Hz}$.

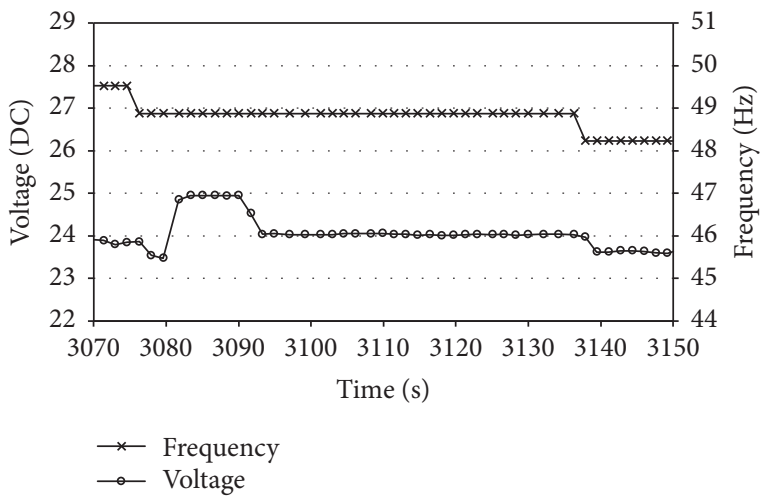

FIGURE 10: System adjustment as the frequency decreases by $1.5 \mathrm{~Hz}$.

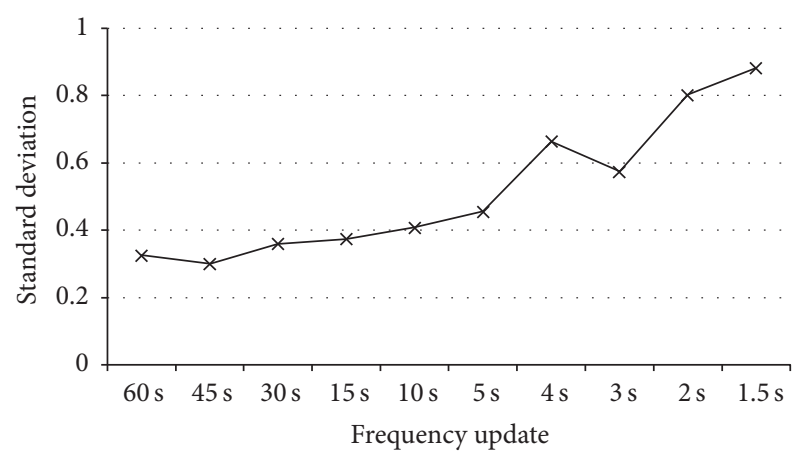

FIGURE 11: Standard deviation at various controller update rates.

The previous test was repeated reducing the time of the intervals between frequency changes, from $60 \mathrm{~s}$ to $1.5 \mathrm{~s}$. Figure 11 shows the standard error deviation as the interval was reduced. The error increases as the time reduces; the system becomes less stable. At higher rates of change, the system cannot maintain the set voltage at the same pace as the frequency.

4.2. Computational Model of the System. A computational model of the hardware was built using Matlab Simulink. The system characterization presented in the previous section was used to model the hydraulic and electric systems present in the test bench. Figure 12 shows the full implementation 


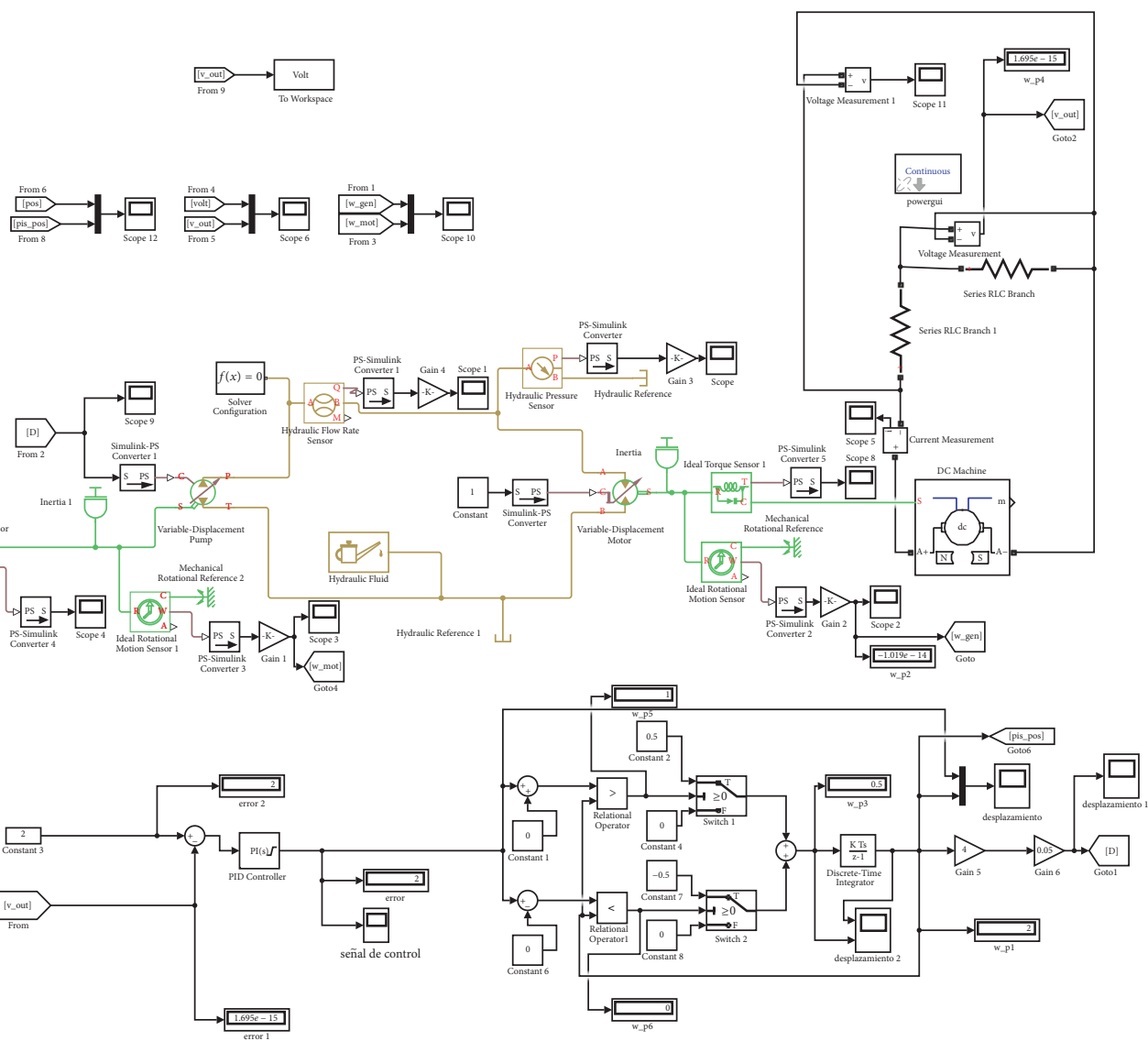

FIgURE 12: Computational model of the hydraulic wind power drive train.

TABLE 1: Model main parameters.

\begin{tabular}{lcc}
\hline Parameter & Units & Value \\
\hline Input shaft speed & $\mathrm{RPM}$ & Variable \\
Electric motor inertial mass & $\mathrm{Kg} \cdot \mathrm{m}^{2}$ & 0.0008 \\
Pump displacement & $\mathrm{cm}^{3} / \mathrm{rev}$ & 18.02 \\
Fluid viscosity & $\mathrm{cSt}$ & 55.4 \\
Fluid density & $\mathrm{Kg} / \mathrm{m}^{3}$ & 890 \\
Bulk modulus & $\mathrm{bar}$ & 14560 \\
Hydraulic motor displacement & $\mathrm{cm}^{3} / \mathrm{rev}$ & 0.29 \\
Electric motor armature resistance & $\mathrm{ohms}$ & 0.6 \\
Torque constant & $\mathrm{N} \cdot \mathrm{m} / \mathrm{A}$ & 0.159 \\
\hline
\end{tabular}

of the model. The simulation included all of the hydraulic components, the DC electric generator, the controller, and the DC linear actuator. All of these models were validated using the experimental data and are summarized in Table 1.

\section{Results and Discussion}

A wind profile obtained from a real wind power turbine was used to evaluate the system. The data depicted in Figure 13 represents the wind measurements obtained over a period of 24 hours, one data point every hour. The data points were used in weighted estimates to span from $32 \mathrm{~Hz}$ to $58 \mathrm{~Hz}$

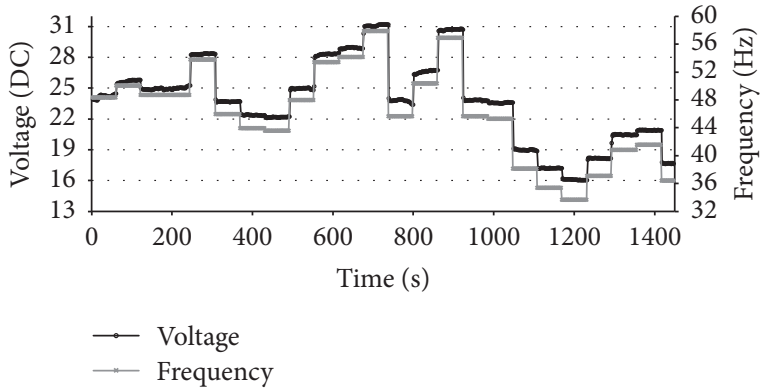

FIGURE 13: Voltage generation with control disabled.

to represent wind speeds between 0.4 and $17.2 \mathrm{~m} / \mathrm{s}$. These frequencies were used to drive the electric motor effectively simulating a variable wind speed.

An initial test evaluated the response of the system as the simulated wind was being changed. In this first test no control was enabled. The electric generator was connected to a $24 \mathrm{~V}$ gear motor to simulate a constant load. The gear motor was estimated to consume an approximate $6 \mathrm{~W}$ of power. The results of this test are shown on Figure 13. The variable hydraulic pump was adjusted at the beginning of the test to generate $24 \mathrm{~V}$ at $47 \mathrm{~Hz}$. The voltage at the generator follows the same path as the driving frequency of the electric 


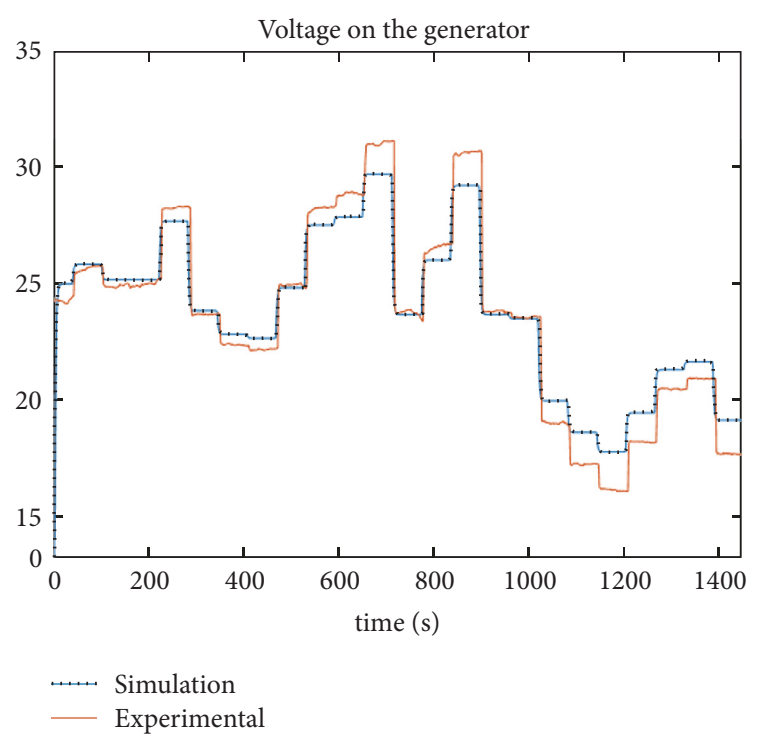

FIgURE 14: Voltage output for a varying wind speed input with control disabled.

motor, as expected. This case represents a fix gear ratio drive train, where the connection between the nacelle and the electric generator is fixed. This means the amount of power captured from the wind is reduced when the wind speed is lower than the nominal wind speed. However, if the wind speed is higher than the nominal value, the aerodynamic efficiency of the turbine is reduced to accommodate the optimal generator speed. At a certain high wind speed above the cut-off speed the nacelle is repositioned so that the turbine spins at a lower RPM. The generator output shown in Figure 13 demonstrates that undesirable variable voltage outputs are obtained at variable winds speeds; this system would be inefficient because the generated electric power would need to be rectified and regulated in order to be used by an electrical application.

The computational model was tested using the disabled controller. A comparison between the experimental data and the simulation is shown in Figure 14. The simulation followed the experimental results very closely with an accuracy as low as $12.5 \%$ at the worst case at 29 volts DC. The simulation was able to dynamically replicate the input signal without a significant time delay.

In the next experiment, the control was enabled and the test was performed under the same conditions described for the first experiment. It can be observed in Figure 15 that the system automatically adjusts itself to maintain a constant $24 \mathrm{~V}$ despite the input frequency. Overshoots can be observed when the frequency changes significantly; however, the voltage returns to the set-point within and average of $15 \mathrm{sec}$. These overshoots could be reduced if a hydraulic accumulator or another energy storage device was added to the system. A hydraulic accumulator is a device that captures hydraulic energy by storing pressurized fluid in a vessel; the pressurized vessel will increase its pressure as more fluid is pushed into the accumulator. Likewise the pressurized energy is released when the fluid is evacuated from the vessel. The

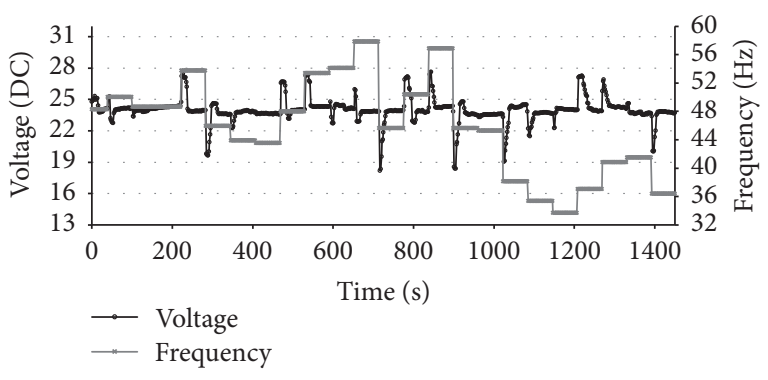

FIGURE 15: Hydraulic wind power drive train with enabled controller.

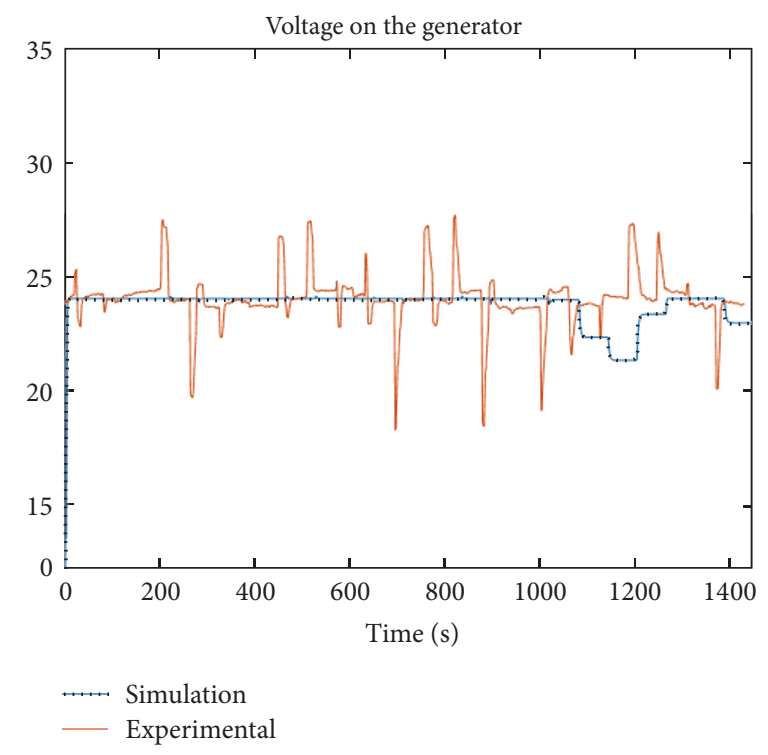

FIGURE 16: Voltage output for a varying wind speed input with control enabled.

accumulator contains a gas chamber that is allowed to change in volume such that when pressurized fluid rushes into the accumulator, the gas chamber is compressed, hence storing energy in the form of pressurized gas.

Results by Dutta et al. [17] show an estimated $4.1 \%$ percent increase in energy production on a $50 \mathrm{~kW}$ turbine by adding a $60 \mathrm{lt}$. accumulator. They also revealed how power generation can be regulated by absorbing voltage peaks and drops by adding such a hydraulic component.

The plot in Figure 16 shows a comparison of the simulated and the experimental behavior of the DC voltage generator when the controller is enabled. The simulation results show a lower magnitude of the overshoots when the frequency (wind speed) is changed, which means that the simulated system has not completely captured the dynamic effects of the physical system. There were instances where some drift from the desired voltage value was observed for the region of lower wind speeds recoded between $1100 \mathrm{~s}$ and $1200 \mathrm{~s}$. This means the simulated controller was not able to adjust the angle of the swash plate in the pump to maintain a 24 VDC output at frequencies below $36 \mathrm{~Hz}$. On the other hand, the experimental results also show that the experimental controller used was not able to effectively maintain the desired output at or 
below this simulated speeds corresponding to approximately $14.96 \mathrm{~m} / \mathrm{s}$.

\section{Conclusions}

A system capable of simulating a small wind power turbine drive train fitted with an infinitely variable transmission was built and tested in laboratory conditions. This system was demonstrated to effectively maintain the electric power output constant despite the input conditions at the nacelle, that is, a hydromechanical solution to maintain the RPM of the electric generator constant regardless of the simulated wind speed. The simple control strategy used to maintain the output voltage of the DC generator proved to be an acceptable method to improve wind power turbine generation at speeds higher than $15 \mathrm{~m} / \mathrm{s}$ for a small wind power generator $(10-100 \mathrm{~kW})$. New control strategies will be implemented in the test setup for an improved wind speed range and dynamic behavior. Lastly, the experimental results show that adding an energy storage device could be an effective and inexpensive method to absorb voltage overshoots created by wind gusts and sudden changes in wind direction.

\section{Conflicts of Interest}

The authors declare that they have no conflicts of interest.

\section{References}

[1] P. J. Tavner, J. Xiang, and F. Spinato, "Reliability analysis for wind turbines," Wind Energy, vol. 10, no. 1, pp. 1-18, 2007.

[2] F. Spinato, P. J. Tavner, G. J. W. Van Bussel, and E. Koutoulakos, "Reliability of wind turbine subassemblies," IET Renewable Power Generation, vol. 3, no. 4, pp. 387-401, 2009.

[3] J. Carroll, A. McDonald, and D. McMillan, "Failure rate, repair time and unscheduled O\&M cost analysis of offshore wind turbines," Wind Energy, vol. 19, no. 6, pp. 1107-1119, 2016.

[4] J. Ribrant and L. Bertling, "Survey of failures in wind power systems with focus on Swedish wind power plants during 19972005," in Proceedings of the 2007 IEEE Power Engineering Society General Meeting, PES, usa, June 2007.

[5] A. Froger, M. Gendreau, J. E. Mendoza, E. Pinson, and L.M. Rousseau, "Solving a wind turbine maintenance scheduling problem," Journal of Scheduling, pp. 1-24, 2017.

[6] Y. Su, J. D. Kern, and G. W. Characklis, "The impact of wind power growth and hydrological uncertainty on financial losses from oversupply events in hydropower-dominated systems," Applied Energy, vol. 194, pp. 172-183, 2017.

[7] F. Ben Amar, M. Elamouri, and R. Dhifaoui, "Energy assessment of the first wind farm section of Sidi Daoud, Tunisia," Renewable Energy, vol. 33, no. 10, pp. 2311-2321, 2008.

[8] E. Muljadi and C. Butterfield, "Pitch-controlled variable-speed wind turbine generation," IEEE Transactions on Industry Applications, vol. 37, no. 1, Article ID 903156, pp. 240-246, 2001.

[9] B. Thul, R. Dutta, and K. Stelson, "Hydrostatic transmission for mid-size wind turbines," Wind Energy Plants, pp. 1017-1022, 2011.

[10] M. Deldar, A. Izadian, and S. Anwar, "Reconfiguration of a wind turbine with hydrostatic drivetrain to improve annual energy production," in Proceedings of the 7th Annual IEEE Energy
Conversion Congress and Exposition, ECCE 2015, pp. 66606666, can, September 2015.

[11] J. Schmitz, N. Vatheuer, O. Reinertz, and H. Murrenhoff, "Hydrostatic drive train in wind energy plants," in Proceedings of International Fluid Power Conference and Exposition, pp. 10171022, Las Vegas, 2011.

[12] Z. Yang, M. Krishnamurthy, and J. M. Garcia, "Modeling and control of a continuously variable planetary transmission for a small wind turbine drivetrain," in Proceedings of the ASME 2013 Conference on Smart Materials, Adaptive Structures and Intelligent Systems, pp. 10-1115, Snowbird, UTAH, 2013.

[13] X. Zhao and P. Maißer, "A novel power splitting drive train for variable speed wind power generators," Renewable Energy, vol. 28, no. 13, 2003.

[14] S. Hamzehlouia, A. Izadian, A. Pusha, and S. Anwar, "Controls of hydraulic wind power transfer," in Proceedings of the 37th Annual Conference of the IEEE Industrial Electronics Society, IECON 2011, pp. 2475-2480, aus, November 2011.

[15] A. Pusha, M. Deldar, and A. Izadian, "Efficiency analysis of hydraulic wind power transfer system," in Proceedings of the 2013 IEEE International Conference on Electro/Information Technology, EIT 2013, usa, May 2013.

[16] Danish Wind Industry Association, "Wind Power Generators," Wind Turbine Generators, 2017.

[17] R. Dutta, F. Wang, B. F. Bohlmann, and K. A. Stelson, "Analysis of short-term energy storage for midsize hydrostatic wind turbinel," Journal of Dynamic Systems, Measurement and Control, Transactions of the ASME, vol. 136, no. 1, Article ID 011007, 2014. 


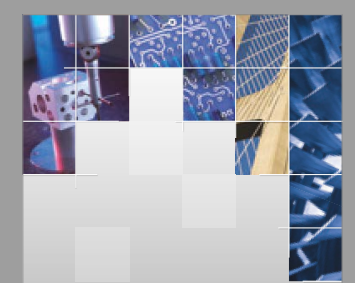

\section{Enfincering}
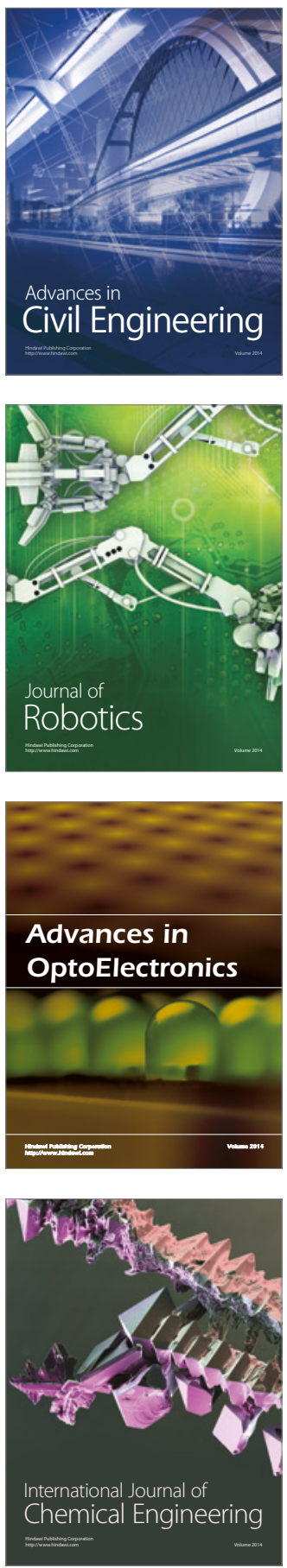

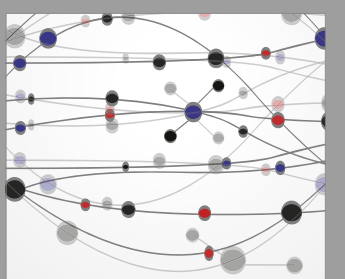

The Scientific World Journal

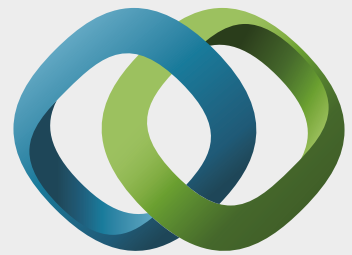

\section{Hindawi}

Submit your manuscripts at

https://www.hindawi.com
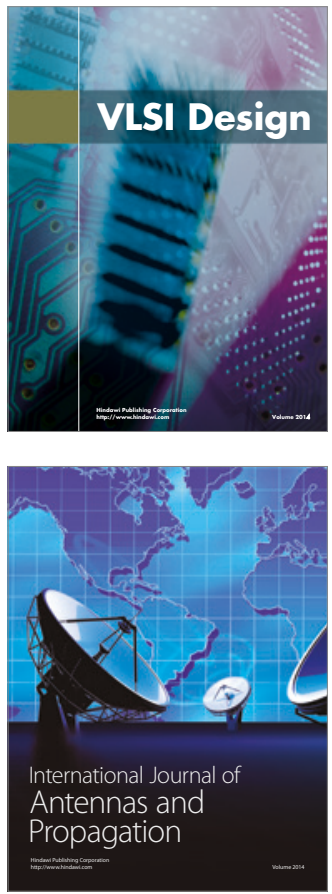

\section{Rotating}

Machinery
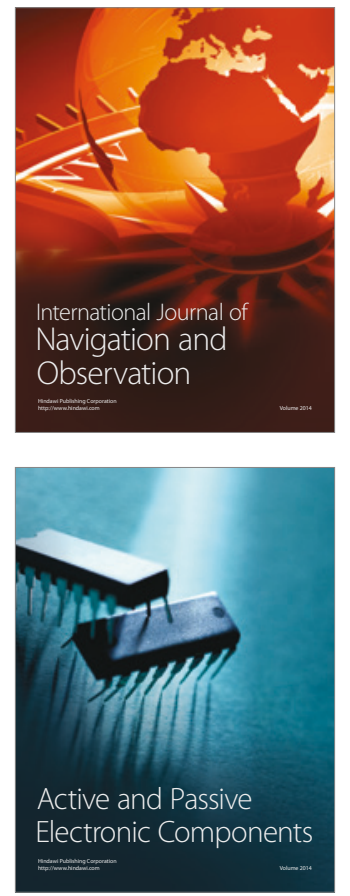
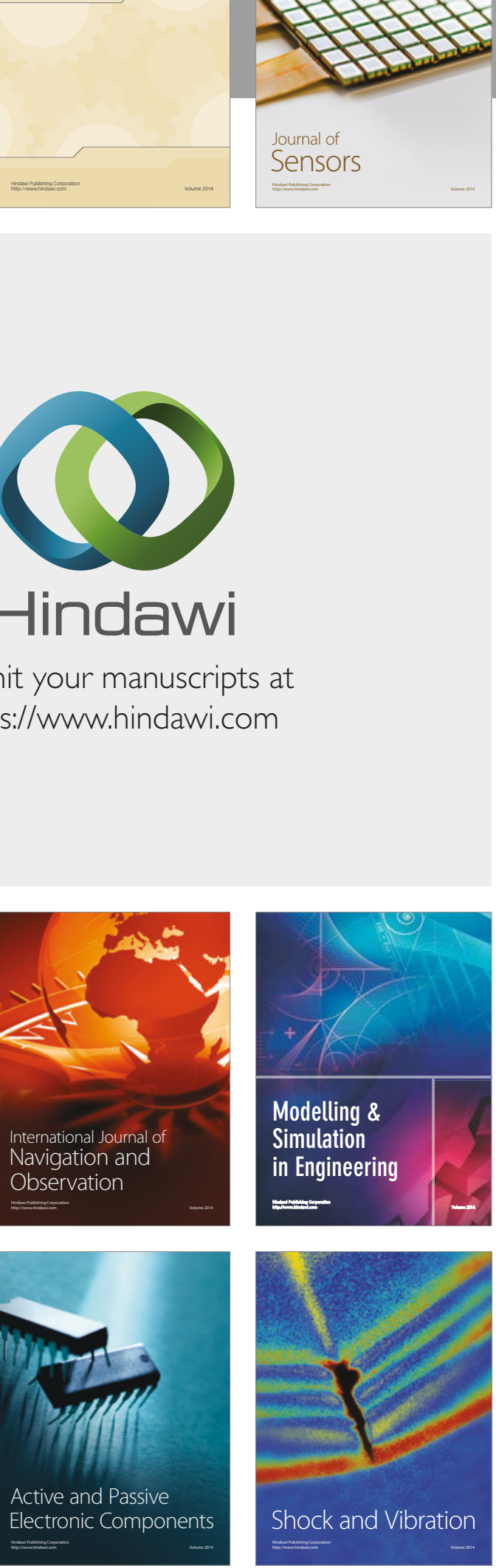
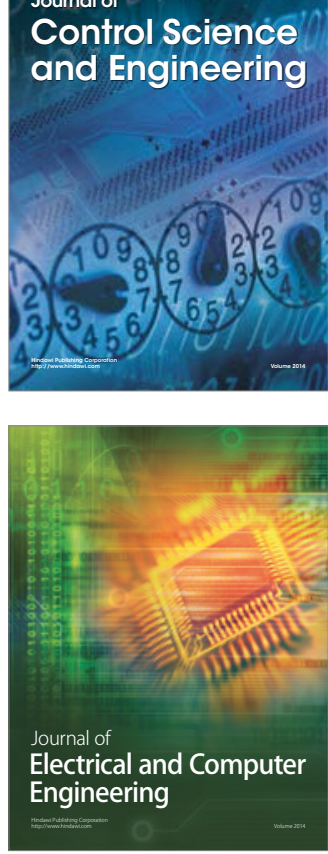

Distributed

Journal of

Control Science

and Engineering
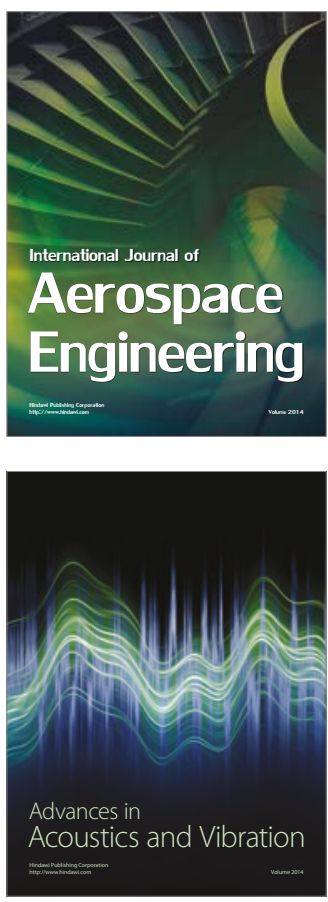

Sensor Networks 